\title{
STANDARDS FOR THE NURSING CARE OF THE FRAIL AGED
}

\author{
L.R. Uys, B.N. Hunt
}

\section{Introduction and problem statement}

The population census of 1985 estimates that of a total population of 4568739 Whites in South Africa, $8,5 \%$ are persons aged 65 years or more. The Human Sciences Research Council at the same time estimated the population undercount and considers that elderly White persons account for $10,36 \%$ of the total White population. Of this growing population of elderly, a study in Durban (City Engineers Department, 1986) indicated that $14,6 \%$ are partly or fully dependent on the clp of others in their daily living. In response to the need for care of this group, the number of institutions geared partly or completely to the care of the frail aged has been growing steadily. The statistics of the National Council for the Aged indicates a growth of subsidized beds for the elderly from 2840 in 1960 to 337000 in 1989 (1989).

The frail aged living within an institution are in an extremely vulnerable position for a variety of reasons: the person's need for care is so great, and care options so limited, that there is little opportunity for really free choices; the person's physical and mental resources may be very limited; support from family is often sporadic and day to day control by the staff of the resident's life is almost total. In such a situation the patient is especially vulnerable, and the need for quality control increases accordingly.

A programme of quality control usually consists of the following phases:

setting of standards based on values;

formulating criteria to measure each standard;

3. developing measuring instruments;

4. identifying problem areas;

5. designing and implementing remedial action;

6. remeasuring the quality of care (Bruwer, 1987).

In the South African setting standards for the care of the frail aged have not been developed in a systematic manner. Although some written and unwritten standards have been generally accepted by funding authorities and welfare organizations, they are too selective and vague for the evaluation of the nursing care to be based on them. There was therefore a need for standards to be developed and instruments to be designed to measure them.

The objectives of this study therefore, were:

1. To formulate standards for the nursing care of residents in frail aged homes which are valid for South Africa, and the criteria that go with these.

2. To develop evaluation instruments to measure the extent to which these

\section{Abstract}

In this project standards for the nursing care of the institutional care of the frail aged were formulated and then validated by groups of nurses. An instrument was then designed to measure to what extent these standards are reached. The instrument was then tested for reliability and validity in a sample of 12 institutions in the Eastern Cape and Natal.

\section{Opsomming}

In hierdie projek is standaarde vir die verpleging van verswakte bejaardes geformuleer en gevalideer deur groepe verpleegkundiges. $n$ Instrument om die bereiking van hierdie standaarde te meet, is daarna opgestel. Die instrument is vir geldigheid en betroubaarheid getoets in 'n steekproef van $/ 2$ inrigtings in die Oos-Kaap en Natal.

standards are met in a home for the elderly and standardize these instruments by assessing reliability and validity.

A standard is a statement describing the expected level of performance against which quality can be evaluated.

A criterium is an indicator which is suitable for measuring a standard.

A frail aged person is a person so classified according to medical assessment.

\section{METHODOLOGY}

This non-experimental research project consisted of the following steps:

- The formulation of the standards and criteria.

- The development and testing of an evaluation instrument.

1. The formulation of the standards and criteria:

The standards and criteria developed by a small group of nurses expert in the field of the care of the aged, were based on a thorough literature survey, and validated by two peer groups consisting of registered nurses working in geriatric settings. The peer groups were constituted by inviting homes in the Eastem Cape and Durban to send a representative each, whom they considered knowledgeable in the area. In this way two groups of five and eight nurses respectively were formed. They were asked to evaluate the standards and criteria for clarity and acceptability, and to add any criteria they felt necessary. Based on the comments of the groups, the final Frail Aged Nursing
Standards Sheet was developed. The Standards Sheet is based both on the problem solving process and basic human needs, and includes the following standards:

1. Nursing needs of the residents are identified on the basis of continuous and complete assessment.

2. Nursing care is planned by a registered nurse.

3. Implementation of planned care is evaluated by a registered nurse at least once in 12 hours.

4. Residents are assisted with any problem with regard to the following, in a way that promotes maximum health and independence:

nutrition;

elimination;

hygiene;

stimulation, orientation and

communication;

mobility;

comfort and pain relief;

sleep;

safety; and

respiration.

\section{The development and testing of the} instrument:

2.1 Instrument: Three measuring instruments were developed based on the standards and criteria of the Standards Sheet:

- one instrument evaluates the institution as a whole, covering structure criteria for areas like the diningroom

dayroom/lounge, corridors, bedrooms and bathrooms, and staffing; as well as process criteria for aspects such as diets, and programmes. It consists of 97 items, and allows for a judgement of "yes", "yes, partially", "no", and "not applicable or not observed". Data are obtained mostly through observation, with only the last three sections necessitating an interview

- one instrument looks at the frail aged unit(s). It contains 28 items, and in the same format as the first, addresses mostly process criteria, and data are obtained mostly through observation.

- the last instrument consists of 124 items, and evaluates the care of a single resident. The format is the same as the other two. and a record review and observation are used to collect the data. Cue sheets were developed for all three instruments. A pilot study was done on five patients and minor alterations were done.

\subsection{Sample:}

Out of the seven regions into which the SA Nursing Association has divided the country, a convenient sample of two, namely the 
Eastern Cape and Natal were chosen for testing the instrument.

The sampling frame was obtained through the Department of Health Services and Welfare (House of Assembly) regional offices. Although relevant authorities for other population groups were contacted, no information could be obtained. It was therefore decided to limit the study to the facilities for White residents. The sampling frame is summarized in Table 1. To get an even spread of urban and rural facilities, it was decided to use only homes outside Por Elizabeth in the Eastern Cape (rural sample), and only homes in Durban and

Pietermaritzburg in Natal (urban sample). Only these areas are reflected in the sampling frame.

The facilities catering for the frail aged were stratified according to size, and a random sample was then drawn from a random number table. Only one of the homes, a small private home in Durban, refused to participate in the study, and an alternative was drawn randomly.

In each home the questionnaire about the institution was filled in, and a questionnaire about each unit catering for the frail aged was completed. In each institution three to five residents were conveniently selected, and the resident questionnaires filled in on them. The fieldworker usually arrived at the home at $07 \mathrm{~h} 00$, and then followed nurses getting residents out of bed. The first five residents so observed became the sample. There was some effort to include bedridden, chairbound and ambulant residents. In small units only three residents were included.

All three of the field-workers participating in the study were registered nurses. with raters, and should be changed, eg "No locks on bathroom doors". The most confusion in this questionnaire, however, was caused in the section on assessment. The time the assessment was done (how soon after admission it was done), influenced the rating. When the time was not given on the record, raters reacted differently, and rated differently.

However, the instruments all show a satisfactory inter-rater reliability.

A cluster analysis was done to test internal consistency. Although the data are not particularly suitable for this kind of calculation, residents from the same homes tended to cluster together, indicating that these residents seem to be receiving the same kind of care. This is an indication of internal consistency.

\section{Validity:}

Content validity of the instrument was accepted on the basis of the content validity of the standards and criteria, as validated by the peer groups.

The construct that was used to test construct validity, was that the care in different residences would be significantly different from each other. This is a rational construct, due to the wide range of funding authorities in charge of the homes in the sample, which leads not only to wide variance in funding, but also in policies.

To calculate the significance of the difference between the residences, the Kruskal-Wallis test was used on the total scores of the residents. This was found to be 38,5 , which is significant on the 0,01 level, which means that here is a significant difference between the different residences. Construct validity can therefore be accepted.

\section{TABLE 1.}

\begin{tabular}{|c|c|c|c|c|c|c|}
\hline \multicolumn{7}{|c|}{ SAMPI.ING FRAME OF INSTITLTIONS WITH FRALL AGED UNITS. } \\
\hline & Number & Ratio & Sample & \multicolumn{2}{|c|}{$\begin{array}{cc} & \text { NaTAI } \\
\text { Number } & \text { Ratio }\end{array}$} & Sample \\
\hline Small (less than 25 residents) & $\mathbf{0}$ & 0 & 0 & 7 & 1 & 1 \\
\hline Medium (25 to 75 residents) & 10 & 2 & 6 & 11 & 2 & 2 \\
\hline Large (more than 75 residents) & 4 & I & 2 & 6 & 1 & 1 \\
\hline TOTAL. & 14 & & 8 & 24 & & 4 \\
\hline
\end{tabular}

\section{RESULTS}

\section{Sample Description:}

The sample was implemented as planned. There were a total of 728 frail residents in the 16 units, and 52 of them (7\%) were evaluated individually. The 12 institutions represented 11 different funding agencies.

\section{Reliability:}

There was some difficulty in measuring interrater reliability, because only four homes were seen by two raters, giving six units and 13 residents. Mc Nemar's correlation could not be used, because there were too many empty cells. It was finally decided to take the institutions and unit marks together, and the residents' marks as a second batch of data, and use the Spearman Rank Correlation Coefficient. In this way the reliability of the residents and units questionnaires were found to be 0,916 , while the reliability of the resident questionnaire was 0,792 .

In the resident questionnaire there were a few negative criteria, which caused confusion

\section{Discrimination:}

Although all the items should be kept in the instrument in order for the instrument to have content validity as far as the Standards Sheet is concerned, it was thought that some items might discriminate better than other between the residences in which higher quality care was given, and those in which lower quality care was given. The discrimination was calculated according to the formula adapted from that given by Mehrens and Lehman (1975):

Discrimination Index $=$ Scores by upper half - Scores by lower half Total possible score for half of sample

The item discrimination indexes found were generally low. Only 18 items had an index of higher than 0,3 (as perfect discrimination index is 1 ).

These 18 items were:

Higher than 0,4

lavatory accessible to wheelchair and attendant

adequate sluicing facilities in sluice room fire drill/practice was done during last six months

rooms have large labels

a complete initial assessment is done on residents

a psychiatric history is recorded.

Higher than 0,3

attractive, comfortable dayroom available ramps outside the building

bath accessible on 3 sides

hoists available

disaster plan available

staff chats to residents

suctioning equipment in working order assessment of memory and use of prosthetic aids included recording data about family and friends, general economic data

recording data about medical history, current diagnosis and treatment resident receives special diet if necessary complaints of pain receive adequate attention.

It would seem that many of these items have to do with an adequate assessment, safety, and easy handling by staff of residents.

\section{Conclusion}

The three instruments designed to measure the quality of nursing care of the frail aged in institutions seem to be both reliable and valid. They can distinguish between homes giving better and poorer care, and can identify specific problems in an institution. The use of these instruments as part of a Quality Assurance Programme in an institution should therefore make a contribution to the maintenance and improvement of quality of care.

The three instruments and their cue sheets will shortly be available from the publication section of the SA Nursing Association in Pretoria.

\section{REFERENCES}

Bnwwer, A. Quality control in nursing. Unpublished D. Cur Dissertation UPE, 1986.

City Engineers Deparment, Durban, 1986 Housing of the Aged: a profile of the elderly white community in Durban. City Engineers' Dept (Town Planning Branch; Research Section).

Mehrens, w.a. and Lehmann, J.J. Measurement and evaluation in education and psychology. Second Ed. New York: Holt, Rinehant and Winston 1978.

National Council for the Aged (1989). Personal communication Chairman.

\section{AUTHORS}

LEANA R. UYS. D. Soc. Sc. U.O.F.S. Professor, Department of Nursing, University of Natal: Durban

NOELLE HUNT. M. Soc. Sc. U.N. Senior Lecturer Department of Nursing, University of Natal: Durban

This research was supported by a HSRC grant We would like to thank the following people for their assistance at different stages of the research: Mrs L. Coetzee (SANA), Ms J Ueckermann (Frere Nursing College), Mrs L. Cremer (Durban) 